\title{
Establecimiento in vitro de arándano (Vaccinium corymbosum L)
}

\author{
In vitro establishment of blueberry \\ (Vaccinium corymbosum L)
}

Ana Hine-Gómez'
Ana Abdelnour-Esquivel²

Fecha de recepción: 22 de enero del 2013

Fecha de aprobación: 26 de mayo del 2013

Hine, A; Abdelnour A. Establecimiento in vitro

de arándano (Vaccinium corymbosum L).

Tecnología en Marcha. Vol. 26, № 4. Pág 64-7I.

Investigadora. Instituto de Investigación y Servicios Forestales (INISEFOR), Universidad Nacional, Heredia, Costa Rica. Teléfono 2562-4606. Correo electrónico: ahine@una.ac.cr

2 Catedrática, investigadora. Centro de Investigación en Biotecnología, Tecnológico de Costa Rica. Cartago, Costa Rica. Teléfono 2550-9029. Correo electrónico: aabdelnoun@itcr.ac.cr 


\section{Palabras clave}

Arándano; micropropagación; estacas; brotación; BAP (bencilaminopurina); 2ip (isonteniladenina) y CPPU (Forclorofenurón).

\section{Resumen}

El arándano es un arbusto de la familia de las ericáceas, del género Vaccinium, al cual pertenecen varias especies, entre las que se reconoce $V$. corymbosum. Debido al alto valor medicinal y nutricional de sus frutos, estas plantas se consideran de gran interés económico y una alternativa de producción para agricultores de zonas altas. Para desarrollar la metodología de propagación masiva in vitro, se tomaron explantes provenientes de plantas adultas de arándano (variedad Avonblue) de la Estación Experimental Fraijanes de la Universidad de Costa Rica, en Alajuela. Para el establecimiento in vitro, las estacas fueron sometidas a cuatro distintas desinfecciones, de igual manera se evaluó y comparó el efecto sobre la brotación de yemas de las citocininas 2iP ( ${ }^{6} 6$ [2-isopentenil]adenina, isopenteniladenina), BAP (6-(benzilamino)-9-(2-tetrahidropiranil)-9H-purina, bencilaminopurina) y CPPU ( $\mathrm{N}$-(2-cloro-4-piridil)$\mathrm{N}$-fenilurea, Forclorofenurón) en una concentración de 2,5 $\mathrm{mg} \mathrm{L}^{-1}$. Se encontró que la utilización de brotes tiernos de las plantas maduras y la desinfección, que consistió de hipoclorito de sodio al I,5\% y 0, I\% de Tween 20 por 40 minutos, permitió el mayor porcentaje de explantes asépticos y que la adición de CPPU indujo el mayor número de brotes a partir del explante inicial, sin embargo, el 2ip promovió la mayor longitud de los brotes.

\section{Key words}

Blueberry; micropropagation; cuttings; shoots; BAP (bencyl aminopurine); 2ip (isopentenyl adenine); CPPU (Forclorofenuron).

\begin{abstract}
Blueberry is a shrub of the Ericaceae family, that belongs to the genus Vaccinium, which comprises several species, among them $V$. corymbosum. Due to the high medicinal and nutritional value of the fruit, these plants are considered of great economic value and a production alternative for upland farmers. In order to establish this species in vitro, explants were taken from adult plants (variety Avonblue) from Fraijanes Experimental Station of the University of Costa Rica, Alajuela. For in vitro establishement, cuttings were subjected to four different disinfection procedures, likewise evaluated and compared, the effect on budding of various cytokinins as 2iP (N6 [2-isopentenyl] adenine, isopentenyladenine), BAP (6 - (benzylamino) -9 - (2-tetrahydropyranyl)$9 \mathrm{H}$-purine, benzylaminopurine) and CPPU (N-(2chloro-4-pyridyl)- $N$ '-phenylurea, Forclorofenuron) at a concentration of $2.5 \mathrm{mg} \mathrm{L}-\mathrm{I}$. It was found that the use of young cuttings from mature plants allowed the highest percentage of aseptic explants when a disinfection solution was sodium hypochlorite at $1.5 \%$ and $0.1 \%$ Tween 20 for 40 minutes and the addition of CPPU induced highest number of shoots from initial explant, however, 2ip promoted the greatest length of shoot.
\end{abstract}




\section{Introducción}

El arándano (Vaccinium corymbosum L) es un arbusto perenne cuyo hábitat se encuentra principalmente en las regiones frías del Hemisferio Norte, aunque también hay especies tropicales. Este género contiene alrededor de 450 especies y pertenece a la familia Ericaceae (Madriz, 1999). Sus frutos son bayas de color oscuro, azuladas o rojizas, ricas en antocianos y minerales, por lo que se les atribuye un alto valor medicinal y nutricional, convirtiéndolo en una especie de gran interés económico (INTA, 20II). Es una especie de gran interés económico en países como Estados Unidos, Canadá y más recientemente Argentina y Chile, donde la demanda está aún insatisfecha (Plata, 1998, Fabiani, 2002). Su importancia comercial y biológica ha despertado el interés de establecer plantaciones, sin embargo, la propagación vegetativa utilizada tradicionalmente en arándano no es una opción para la producción masiva de material de siembra, ya que se requeriría una gran cantidad de plantas madre, debido a la pobre habilidad de enraizamiento de las estaquillas (Ostroluka et al., 2007). El arándano puede ser propagado in vitro regenerando brotes a partir de segmentos de hoja, brotación directa de yemas a partir de estacas, tanto de plantas maduras como juveniles, y varios autores mencionan la obtención de gran cantidad de brotes utilizando las diferentes vías de regeneración de las plantas (Brissette et al., 1990, Cao y Hammerschlang, 2002, Fira et al., 2008, Debnath y MacRae, 200 I).

En Costa Rica, el arándano ha despertado gran interés ya que es horticulturalmente promisorio, tiene gran potencial para la exportación e industrialización; además, el país cuenta con suelos y climas favorables para este cultivo, razones por las que se incluyó como línea de investigación en el área de cultivos no tradicionales del Programa Nacional de Fruticultura (Madriz, 1999, Montero, 2010). Desde hace alrededor de 20 años se mantiene una pequeña colección de campo (cinco híbridos) en la Estación Experimental Fraijanes de la Universidad de Costa Rica, con materiales introducidos del Banco de Germoplasma Clonal de la USDA en Corvallis, Oregón (Dr. Jorge Morera, Profesor de Agronomía, Universidad de Costa Rica, comunicación personal).

Algunas de estas introducciones de arándano han mostrado buen desarrollo, lo que podría significar la posibilidad de insertarlos en la agricultura costa- rricense y generar así una alternativa más de producción para los agricultores, no solo de Fraijanes sino también de otras zonas de nuestro país con condiciones similares. El establecimiento de una metodología de reproducción in vitro de esta especie permitiría aumentar rápidamente el número de plantas existentes, así como garantizar la disponibilidad de material para respaldar las demandas para la siembra. Por estas razones, esta investigación se dirigió al establecimiento y brotación de estacas de arándano de la variedad Avonblue provenientes de plantas maduras.

\section{Materiales y métodos}

\section{Material experimental}

Como material experimental se emplearon estacas de arándano de la variedad Avonblue, provenientes de plantas adultas que se mantienen en la Estación Experimental Fraijanes de la Universidad de Costa Rica. Las estacas fueron enraizadas y mantenidas en condiciones de invernadero, donde fueron asperjadas con una solución de $4 g L^{-1}$ de agrymicin $®$ y $4 \mathrm{~g} \mathrm{~L}^{-1}$ de benlate $\AA$ tres veces por semana durante I5 días. Estas plantas se utilizaron como fuente de explantes para la experimentación.

\section{Desinfección del material}

Estacas de 2,5 cm de largo con un nudo fueron desinfectadas e inoculadas en el medio de cultivo básico descrito por Murashige y Skoog (M\&S) (1962), complementado con 2,5\% de sacarosa y 0,8\% de agar, el pH se ajustó a 5,7. Cada unidad experimental consistió de un tubo de ensayo con $10 \mathrm{ml}$ de medio. Se plantaron 25 repeticiones por tratamiento. El material cultivado se colocó en el cuarto de crecimiento a una temperatura de $21^{\circ} \mathrm{C}$, con un fotoperiodo de 12 horas y 850 lux de intensidad lumínica. La evaluación de la contaminación se realizó cada tres días durante 18 días.

Se evaluaron tres tratamientos de desinfección y en general consistieron en colocar las estacas maduras bajo un flujo constante de agua durante $30 \mathrm{~min}$., para luego lavarlas con agua y jabón antibacterial (Bactex $\left.{ }^{\circledR}\right)$ al $1 \% \mathrm{v} / \mathrm{v}$, durante 10 min. en agitación y se cepillaron suavemente para eliminar los contaminantes adheridos a la superficie. Las estacas fueron enjuagadas con abundante agua. En todos los casos, una vez concluida la desinfección, 25 estacas de cada 
tratamiento fueron enjuagadas tres veces con agua destilada estéril e inoculadas directamente en el medio de cultivo M\&S (1962). Para los tratamientos (A) y (B) (que se describen a continuación), otras 25 estacas fueron adicionalmente incubadas en la solución antioxidante descrita por Brissette y colaboradores (Brissette et al., 1990), que consiste en 7,5 mg de ácido cítrico y 5 mg de ácido ascórbico en 100 $\mathrm{ml}$ de agua destilada estéril, para luego inocularse en el medio de cultivo.

En el primer tratamiento evaluado (A), las estacas fueron sumergidas en una mezcla de $2 \mathrm{~g} \mathrm{~L}^{-1}$ de agrymicin y $2 \mathrm{~g} \mathrm{~L}^{-1}$ de benlate por 30 min., en agitación. Posteriormente se sumergieron en alcohol al $70 \%$ por I minuto seguido de un lavado con agua destilada, por último las estacas se incubaron en una solución de hipoclorito de sodio al $2 \%(\mathrm{v} / \mathrm{v})$ y $0,1 \%$ de Tween 20 por 20 min. Concluido el periodo, se realizaron tres lavados con agua destilada estéril en la cámara de trasferencia de flujo laminar. El tratamiento (B) fue similar al tratamiento (A), pero las estacas se colocaron en un baño ultrasónico con el jabón y luego se desinfectaron con hipoclorito de sodio al 1,5\% por 10 minutos; concluido este tiempo se realizaron los tres lavados con agua destilada estéril en la cámara de flujo laminar. Por último, para las estacas en el tratamiento (C) se siguió el mismo procedimiento que en (A) pero la desinfección consistió de hipoclorito de sodio al I,5\% y $0,1 \%$ de Tween 20 por 40 minutos, para finalizar con los tres lavados con agua destilada estéril en la cámara de flujo laminar y la inoculación en el medio de cultivo.

Se incluyó un tratamiento adicional (D), utilizando estacas inmaduras y su desinfección fue similar al tratamiento $(C)$.

Inducción a la brotación de estacas inmaduras de arándano

Las estacas inmaduras de arándano fueron inoculadas en el medio de cultivo Lloyd y McCow (198I) (WPM, Woody Plant Medium), complementado con 3\% de sacarosa, 0,8\% de agar, pH 5,7. Se evaluó la concentración de $2,5 \mathrm{mg} \mathrm{L}^{-1}$ de tres diferentes citocininas (2iP, BAP y CPPU), más el testigo (sin reguladores del crecimiento) con 15 repeticiones por tratamiento. El medio de cultivo fue esterilizado por autoclave durante $20 \mathrm{~min}$. a 1,2 ATM $/ \mathrm{cm}^{2}$ de presión, para alcanzar una temperatura de $121^{\circ} \mathrm{C}$. Cada unidad experimental consistió de un tubo de ensayo con $10 \mathrm{ml}$ de medio. El material cultivado se colocó en el cuarto de crecimiento a una temperatura de $21{ }^{\circ} \mathrm{C}$, con un fotoperiodo de 12 horas luz y una intensidad lumínica de 850 lux. La evaluación del material se realizó cada ocho días durante las primeras cinco semana y se efectuó una última evaluación en la semana diez.

\section{Análisis de los datos}

Los datos se analizaron con el programa ESTADÍSTICA, aplicándoseles un análisis de varianza (Spjotoll/Stoline test).

\section{Resultados}

\section{Desinfección del material}

Al utilizar estacas maduras para la introducción al cultivo in vitro, se observó una alta contaminación en los tratamientos de desinfección evaluados en los que se utilizaron estacas maduras ( $A, B$ y $C$ ), a partir de los tres días de cultivo, contaminación que se hizo recurrente y aumentó conforme transcurrió el tiempo. A los 18 días de cultivo, los porcentajes de contaminación de las estacas en estos tratamientos de desinfección fueron de $98 \%$, 92\% y $85 \%$ respectivamente.

Cuando se utilizaron estacas inmaduras (tratamiento $D$, similar a $C$ pero el desinfectante utilizado fue hipoclorito de sodio al I,5\% (v/v) por 40 minutos), la contaminación se observó a partir del día 6 (4\% de contaminación), para el día 9 se observó un 25\% de contaminación, porcentaje que se mantuvo constante hasta el día I8. La contaminación en los cuatro tratamientos se debió a la presencia de hongo sobre el explante; no se observó contaminación por bacteria en ninguno de los tratamientos (figura I).

\section{Oxidación}

En los tratamientos de desinfección A y B, en los que se utilizó adicionalmente la incubación de los explantes en la solución antioxidante, no se observó oxidación ni cuando se cultivaron sin el lavado ni con el lavado de las estacas con la solución antioxidante, previo al cultivo in vitro (datos no se muestran). 
Inducción a la brotación de estacas inmaduras de arándano

Al evaluar el efecto de los reguladores de crecimiento tipo citocinina, 2ip, BAP y CPPU en la brotación de las yemas de las estacas inmaduras, en una concentración de 2,5 $\mathrm{mg} \mathrm{l}^{l^{-1}}$, se determinó, de acuerdo con el análisis de varianza, que para el número de brotes nuevos por estaca, la longitud de los brotes nuevos y el número de hojas por brote, se presentaron diferencias significativas $(P=0.000)$, tanto entre los tratamientos como entre los tratamientos y los días después del cultivo. Se observó mayor número de brotes por estaca en el tratamiento con CPPU, con una media de dos brotes (figuras 2A y 3D). La mayor longitud de los brotes nuevos y el mayor número de hojas por brote se observó en el tratamiento con 2ip, con una media de $1,61 \mathrm{~cm}$ (figuras $2 \mathrm{~B}$ y $3 \mathrm{~B}$ ) y ocho hojas por brote (figura $2 \mathrm{C}$ ) respectivamente y su efecto fue similar al del testigo.

\section{Discusión}

La evaluación de la contaminación, tanto a los 3 días como a los 18 días de cultivo, mostró que los mayores porcentajes correspondieron a estacas maduras (tratamientos A, B, C) y que en el tratamiento de desinfección D, el cual se llevó a cabo con estacas inmaduras, se observaron los menores porcentajes de contaminación, mostrando un $75 \%$ de estacas asépticas al día 18. Estos resultados confirman lo señalado por otros investigadores con respecto a la dificultad para establecer in vitro material proveniente de campo, aún dando a las plantas madre un manejo fitosanitario previo a la colecta (George et al., 2008). La contaminación fúngica fue muy significativa en estos ensayos de desinfección y, de acuerdo con Villegas (1990) y Razdan (2003), los hongos son agentes contaminante muy comunes en los ensayos de cultivo de tejidos, sobre todo cuando se utiliza tejido adulto de plantas que crecen en campo, como el material utilizado en este experimento en los tratamientos A, B y C. Contrariamente al material joven o inmaduro, el material más maduro ha estado en contacto con su medio por largo tiempo y ha desarrollado relaciones no patogénicas con otros organismos del ambiente, lo que dificulta la desinfección superficial y hace necesario el uso de fuertes desinfecciones y desinfectantes altamente tóxicos, como el hipoclorito de sodio y calcio en altas concentraciones, el etanol de $70^{\circ}$ y el cloruro de mercurio (Brissette et al., 1990, Abdelnour y Muñoz, 2005, Ostrolucka et al., 2007, Abdelnour et al., 20I I).

Por lo anterior, el mantenimiento del material experimental en condiciones de invernadero, donde se encuentra más protegido de las condiciones

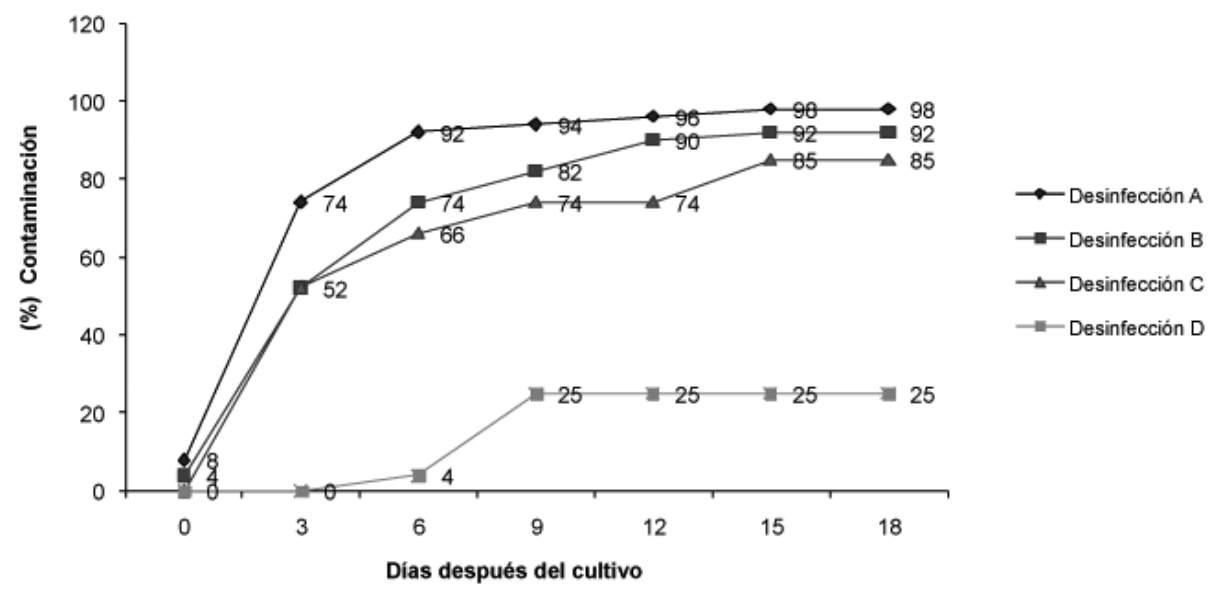

Figura I. Porcentaje de contaminación de los explantes de arándano (Vaccinium corimbosum), después de los tratamientos de desinfección. A: incubación por 30 min en $2 \mathrm{gL}^{-1}$ de agrymicin y $2 \mathrm{gL}^{-1}$ de benlate, en agitación, alcohol de $70^{\circ}$ por I min, seguido de un lavado con agua destilada, Incubación por 20 min en hipoclorito de sodio al 2\% en agitación. B: Similar al tratamiento (A), pero las estacas se colocaron en un baño ultrasónico con el jabón antibacterial y luego se desinfectaron con hipoclorito de sodio al 1,5\% por 10 minutos. C: Similar a (A) pero utilizando hipoclorito de sodio al $1.5 \%$ por 40 min. D: Similar a (C) pero utilizando estacas inmaduras. 
ambientales y se hace posible la aplicación sistemática de agroquímicos para el control de microorganismos, es una estrategia recomedada para obtener mayores porcentajes de explantes establecidos asépticamente durante el proceso de micropropagación. A pesar de que algunos autores informan sobre problemas de oxidación en arándano y otras especies leñosas (Brissete et al., 1990, Méndez, 20 II), en el presente trabajo no se observó este fenómeno, lo que podría explicarse con base en las concentraciones de desinfectantes utilizadas, que fueron suficientemente bajas para no dañar el tejido, pero tampoco fueron efectivas para lograr la desinfección de un alto porcentaje de explantes maduros.

En cuanto al medio de cultivo utilizado, el WPM es el que preferentemente se ha recomendado para arándano, ya sea con la concentración de sales completa, duplicando la concentración de nitrato de calcio o utilizando sequestrene como fuente de hierro, y de acuerdo con los informes disponibles, este medio de cultivo permite el desarrollo de plantas más vigorosas (Reed y Abdelnour-Esquivel 1991, Zhang et al., 2006, Fira et al., 2008).
Al evaluar el efecto de los reguladores de crecimiento tipo citocinina, CPPU, BAP y 2iP (concentración de 2,5 $\mathrm{mgl}^{-1}$ ) sobre la brotación de estacas inmaduras de arandano, se observó que el CPPU presentó mayor eficiencia, siendo significativamente diferente $(P=0.000)$ al resto de las citocininas evaluadas. Las citocininas juegan un papel relevante en el cultivo de tejidos vegetales, especialmente en la inducción de la división celular y el control de la morfogénesis. La evidencia experimental indica que el meristema radical es el principal sitio de síntesis de las citicininas y que estas son traslocadas de ahí a los brotes y la producida por los brotes representa solo una pequeña porción de la sintentizada por la raíz (Taiz y Zeiger, 2008). De acuerdo con George (2008), la baja concentración de citocininas en el brote resulta insuficiente para mantener el crecimiento in vitro, de ahí que el cultivo in vitro de estacas para la inducción de la brotación de las yemas axilares requiere la adición de estos reguladores de crecimiento (Frett y Smagula, 1983, George, 2008, Najaf-Abadi y Hamidoghli, 2009, Kulkamp de Souza et al., 20 I I). Las citocininas derivadas de la adenina, como el BA
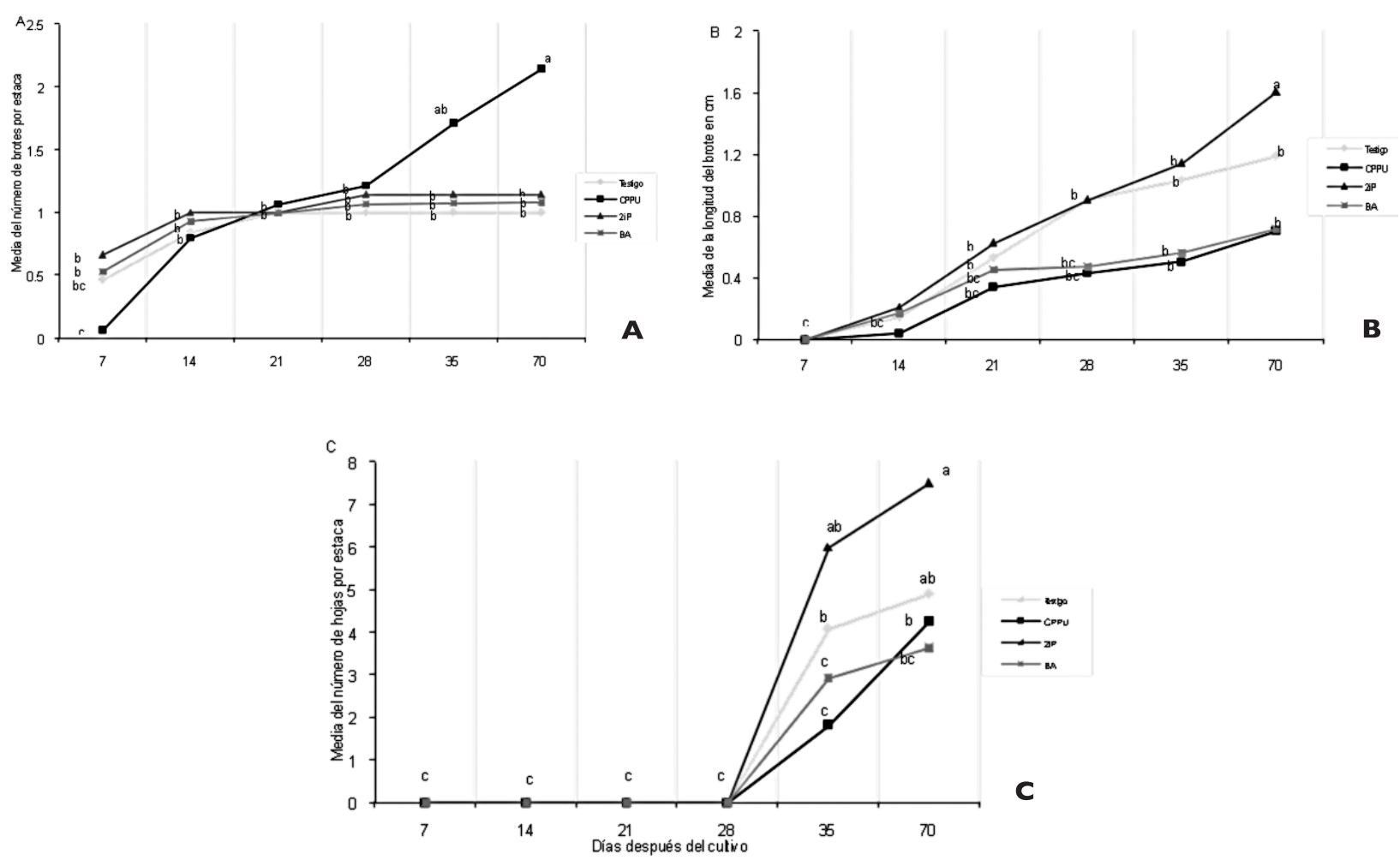

Figura 2. Efecto de la concentración de $2,5 \mathrm{mg}^{-1}$ de 2iP, CPPU (Forclorofenurón) y BAP (bencilaminopurina) sobre la brotación (A), longitud del brote (B) y el número de hojas por brote (C) de estacas inmaduras de arándano de la variedad Avonblue. 

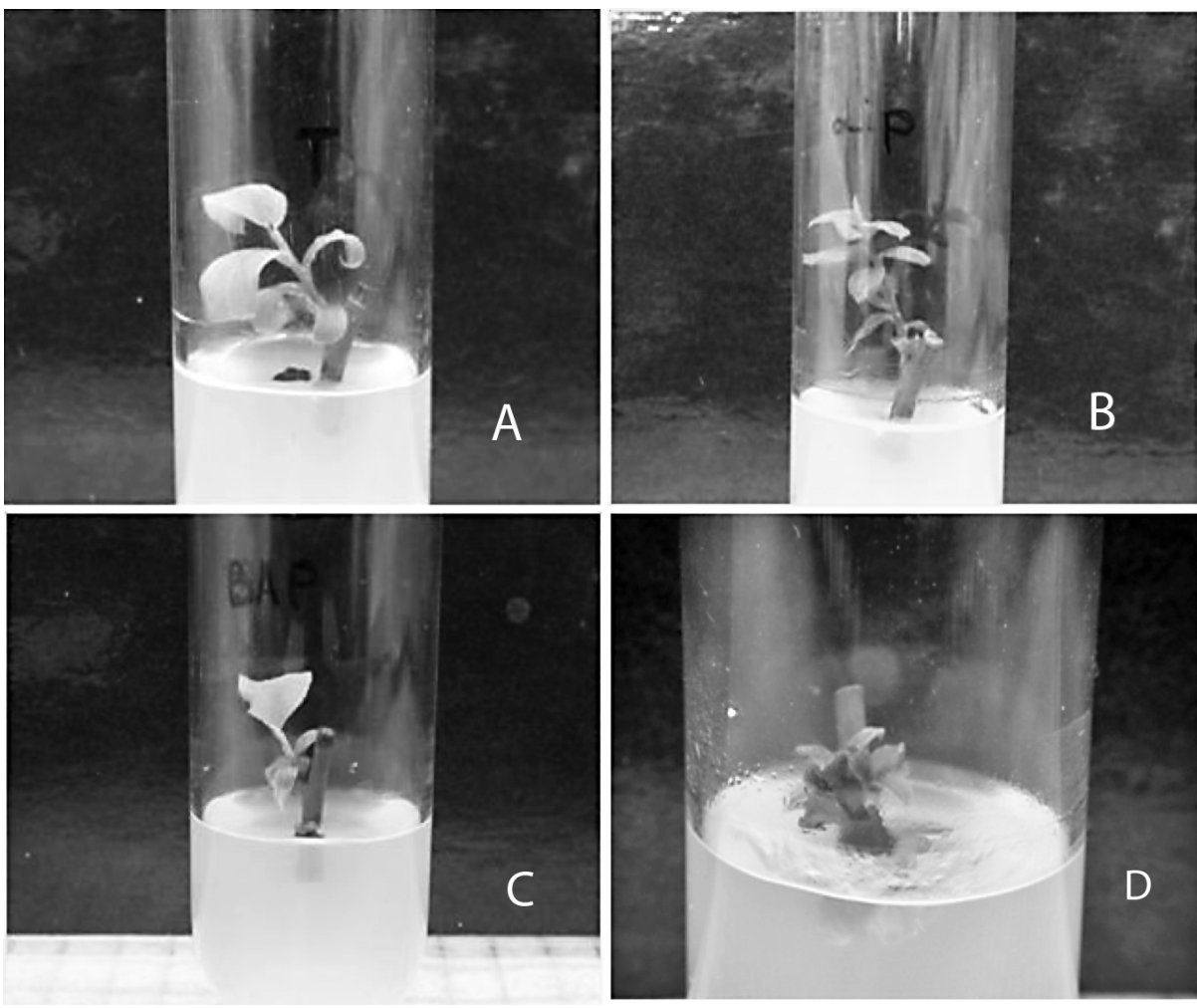

Figura 3. Brotes de arándano inducidos a partir de un Ms sin regulador (A), MS complementado con una concentración de $2,5 \mathrm{mg} / \mathrm{l}$ de $2 \mathrm{iP}(\mathrm{B}), \mathrm{BAP}(\mathrm{C})$, CPPU (D).

y el 2ip, son especialmente efectivas para promover la morfogénesis y se utilizan comúnmente en micropropagación. Por otra parte, las citocininas derivadas de la difenilurea, como el CPPU, pueden ser altamente efectivas para promover la formación de brotes adventicios en el cultivo de microestacas, sin embargo, a pesar de que este tipo de citocininas induce la formación de una mayor cantidad de brotes, estos brotes no se elongan, lo que hace necesario transferirlos a un nuevo medio con BA u otra citocinina de este tipo (Brissette et al., 1990, George, 2008). El efecto del CPPU en las estacas de arándano utilizadas fue claro en nuestro ensayo, ya que esta citocinina promovió la inducción de brotes múltiples, lo que podría sugerir una estrategia de micropropagación para arándano, ya que una vez brotadas las estacas, los brotes podrían ser subcultivados en 2ip, que fue el más efectivo promoviendo la longitud del brote. Estos resultados mostraron la estrategia de utilizar para el establecimiento in vitro de arándano, el medio de cultivo y reguladores de crecimiento con potencial para lograr la micropropagación de esta especie.

\section{Bibliografía}

Abdelnour, A. \& Muñoz, A. (2005). Micropropagación de teca (Tectona grandis). (En línea). Revista Forestal Mesoamericana Kurú 2(5): I- | I. Consultado 20 octubre 2005. Disponible en http://www.itcr/publicaciones/revistakuru/pdf/ ABDELNOUR3 I Ago05.pdf

Abdelnour, A., Aguilar, M. \& Valverde, L. (20I I). Micropropagación de pilón (Hieronyma alchornoides). Agronomía Costarricense $32(2)$.

Brissette, L., Trembla, L. \& Lord, D. (1990). Micropropagation of Lowbush Blueberry from mature field-grown plants. HortScience 25 (3): 349-35I.

Ca, X. \& Hammerschlag, F. (2002). A two step pretreatment significantly enhances shoot organogenesis from leaf explants of Highbush Blueberry c.v. Bluecrop. HortScience 37 (5): 8|9-82|.

Debhath, S.C. \& MacRae, K. (200I). An efficient in vitro shoot propagation of cranberry (Vaccinium macrocarpon Ait) by axillary bud prolifereation. In vitro \& Developmental Biology Plant 37 (2): 243-249.

Fabiani, A., Martínez, C. \& Carlazara, G. (2002). Cultivo de arándano en la zona del Río Uruguay (en línea). Argentina. Consultado 6 de septiembre 2004. Disponible en http:// www.inta.gov.ar/ediciones/idia/fruta/pdf/arandano.pdf 
Fira, A., Clapa, D. \& Badescu, C. (2008). Aspects regarding the in vitro propagation of Highbush Blueberry Cultivar Blue Crop. Bulletin UASVM, Horticulture 65: 104- 109

Frett, J.J. \& Smagula, J.M. (1983). In vitro Lowbushblueberry. Can. J. Plant Science 63: 467-472.

George, E., Hall, M.A. \& De Klerk, G. (2008). Plant Propagation by Tissue Culture. Vol. I. 3 ed. Springer. pp. 2-3, 205-219.

INTA (Instituto Nacional de Nutrición y Tecnología de Alimentos). (20I I). Análisis de antioxidantes: Qué y cómo se deben medir. Consultado 25 octubre 201 I. Disponible en http://portalantioxidantes.com/analisis-de-antioxidantes/

Kulkamp de Souza, A.L., Wupff, M., Corra, L.E., Dutra, J., Da Silveira, M., Silva, S. \& Cara, B. (201I). Desempenho de mudas de mirtilo obtidas por micropagacao ou estaquia. Pesq. Agropec. Bras. 46: 868-874.

Lloyd G. \& McCown, B. (1980). Commercially-feasible micropropagation of mountain laurel, Kalmia latifolia, by use of shoot-tip cultura. Comb. Proc. Intl. Plant Prop. Soc. 30:42 I-427.

Madriz, J.P. (1999). Vaccinium: Especies silvestres neotropicales, perspectivas para la domesticación de nuevos frutales arbustivos en los bosques montanos del neotrópico. Memorias IX Congreso Nacional Agronómico, p. 295.

Murashige, T. \& Skoog, F. (1962). A revised medium for rapid growth and bioassays with tobacco tissue cultures. Physiolgia Plantarum 15: 473-497.

Méndez, D. (20ll). Establecimiento in vitro de Roble coral (Terminalia amazonia).Trabajo final de graduación para optar por el grado de Bachiller en Ingeniería en Biotecnología. Escuela de Biología, Instituto Tecnológico de Costa Rica.
Montero, A. (2010). Comunicación personal. Gerente del Programa Nacional de Frutas no tradicionales del Ministerio de Agricultura y Ganadería (MAG), San José.

Najaf-Abadi, A.J. \& Hamidoghli, Y. (2009). Micropropagation of thornless trailing blackberry (Rubus sp.) by axillary bud explants. Australian Journal of Crop Science 3: 191-194.

Ostrolucka, M., Gajdosova, A., Libiakova, G., Hrubikova, K. \& Bezo, M. (2007). Protocol for micropropagation of selected Vaccinium spp. In: Jain, S.M. \& Haggman, H. (ed.). Protocols for micropropagation of Woody Trees and Fruits. Springer. Pp. 445-455.

Plata, MI. (1998). Micropropagación de cultivares comerciales de arándano libres de enfermedades en Argentina. In: Resúmenes del REDBIO 98. III Encuentro latinoamericano de biotecnología vegetal, REDBIO '98. La Habana. Pp 91-92.

Razdan, M.K. (2003). Introduction to plant tissue culture. 2 ed. Indiana, US: Science Publishers. Pp. 35-40.

Reed, B.M. \& Abdelnour-Esquivel, A. (|99|). The use of zeatin to iniciate in vitro cultures of Vaccinium species. HortScience 26: 1320-1322

Taiz, L. \& Zeiger, E. (2006). Plant Physiology. 4 ed. Sunderland, Massachusetts, US: Sinauer Associates. Inc. Pp. 493-5I 5.

Villegas, A. (1990). Métodos asépticos. Fundamentos teórico-prácticos del cultivo de tejidos vegetales. FAO 105, 21 p.

Zhang, S., Liu, H., Wu, L. \& Li, Y. (2006). Technical systems of blueberry micropropagation in China. Acta Hort. (ISHS) 7| 5: 42 I-426. 